\title{
CALER La cocina como espacio de producción y reproducción de la vida cotidiana
}

VALERIA C. GONZALEZ LIMON'

Licenciatura en Sociología/UAA

¿POR QUÉ LA COCINA?

$\mathrm{T}$

radicionalmente la cocina ha sido un espacio de primordial importancia en la vida cotidiana de los hogares y ahí las mujeres han sido protagonistas de un sinnúmero de actividades que contribuyen a la producción y la reproducción de la vida cotidiana, entre ellas cocinar, estar y encontrarse con los demás miembros del hogar para hablar, compartir o realizar alguna actividad específica.

La importancia de la cocina como un espacio de producción y reproducción de lo cotidiano, y el papel preponderante de la mujer en él, son razones suficientes para justificar el estudio de este tema. Sin embargo, existe muy poca investigación sobre este tema, por lo menos en México.

Lo que suele ser muy común en este país es la referencia a la cocina o a la comida a través de dichos o refranes populares para aconsejar, enseñar, burlarse o hasta alburear a otras personas. Esto habla de su

Agradezco a Silvia Bénard la cantidad de horas que puso en este trabajo, no solamente mientras fue mi maestra en el último taller de investigación en que concluí este texto, sino que también después, discutiendo el tema, organizando el material y editando el manuscrito. 
importancia. Como muestra de ello, he aquí algunos dichos, "dicharachos" y refranes mexicanos:

iA darle que es mole de olla!, "A la mejor cocinera se le queman los frijoles", "El que nace pa' tamal, del cielo le caen hojas", "Andas meneando fuera de la olla", "A quien le dan pan que llore", "Le dan atole con el dedo", "¿A qué hora vas al pan?", " iAquí mis chicharrones truenan!", "Barriga llena corazón contento", "Comerse el mandado", "¿Comiste gallo?", "Con las manos en la masa", "De lengua me como un taco", "El comal le dijo a la olla", "Este arroz ya se coció", "El ajonjolí de todos los moles", "Gallina vieja hace buen caldo" "Nunca falta un negrito en el arroz", "Peor es el chile y el agua lejos", "¿Qué comes que adivinas?", "Se sirvió con la cuchara grande", "Su mero mole", "Son prietitos del mismo arroz", "Tiene atole en las venas", "Te traigo en salsa", "Una sopa de su propio chocolate", "Ya no se cuece al primer hervor"...2

Mi interés sobre este tema no es reciente, aunque se ha ido enriqueciendo por el conocimiento de la sociología, los estudios de género $y$, por supuesto, mi experiencia personal: desde muy pequeña me ha llamado la atención y, de un modo u otro, siempre he tenido cercanía con la cocina. Además, en mi familia, tanto paterna como materna, han sido las mujeres las encargadas "oficiales" de las labores culinarias.

Sin embargo, con las transformaciones sociales y culturales, los roles de las mujeres han ido cambiando y se han multiplicado las actividades que realizan, dentro y fuera de la casa. Por ello, ya no aparece como algo tan obvio el que desempeñen las labores cotidianas del hacer la comida y sean ellas las protagonistas de la cocina. Pese a ello, todavía para muchas familias la organización tradicional de la cocina sigue siendo un referente cultural muy importante; es el lugar de reunión, el momento del día en el que están todos juntos, donde suelen platicar sobre las cosas que han ocurrido en el día -sus alegrías, penas, preocupaciones, triunfos, fracasos, etc.-, el lugar en donde se pueden confiar los secretos, las confidencias y quizá también en donde se hable de las cosas serias.

Y entonces, cómo se "resuelve" esta contradicción: la diversificación

José M. Pérez, Manual práctico Dichos, Dicharachos y Refranes mexicanos, Editores Mexicanos Unidos, México, 1983. 
del trabajo de las mujeres, dentro y fuera de la casa, las ha alejado de su tradicional centralidad en la cocina, y al mismo tiempo, la figura de la mujer como la protagonista central de este espacio sigue siendo un referente primordial de la vida cotidiana en los hogares.

Si bien reconozco que no hay razón para argumentar que la mujer deba seguir ocupando ese lugar que le ha dado la tradición, quiero argumentar que a pesar de que el cocinar ha sido un quehacer fundamental en la producción y reproducción de la vida cotidiana, tanto como el trabajo remunerado y fuera de casa, ha pasado desapercibido y, consecuentemente, ha sido un ámbito poco reconocido y valorado socialmente. Por eso, esta pequeña investigación se ha centrado en reconocer y desvelar el valor del cocinar y la centralidad que han tenido las mujeres en él.

En la cocina se requiere tanto de la actividad mental como manual, todos lo recursos de la inteligencia y la memoria se movilizan; es necesario organizar, decidir, prever; memorizar, adaptar, modificar, inventar, combinar, tomar en cuenta los gustos y necesidades de cada miembro de la familia, satisfacer gustos, dietas especiales, etc.

Luce Giard menciona que en Francia y otras partes del mundo, el que sean todavía las mujeres quienes llevan a cabo en general el trabajo cotidiano de hacer de comer, es signo de un estado social y cultural, y de la historia de las mentalidades, manifestación de una esencia femenina ${ }^{3}$. Y continúa la autora:

Si juzgamos necesario interesarnos dentro de este estudio en este ejemplo de prácticas, y no en otro, se debe al papel central que tiene en la vida cotidiana de la mayor parte de las personas, independientemente de su situación social y de su relación con la "cultura culta", o con la industria cultural de masas. Además las culturas alimentarias constituyen un dominio en donde la tradición y la innovación importan de igual modo, donde el presente y el pasado se mezclan para atender la necesidad del momento, proporcionar la alegría del instante, adecuarse a la circunstancia. Con su alto grado de ritualización y su poderosa inversión afectiva, las actividades culinarias son para muchas mujeres de todas las edades un lugar

Michel de Certau, Luce Girad y Pierre Mayol, La invención de lo cotidiano 2. Habitar, cocinar, Universidad Iberoamericana, ITESO, México, 1999, p. 153. 
de felicidad, placer e inversión. Estas cosas de la vida reclaman tanta inteligencia, imaginación y memoria como las actividades tradicionalmente consideradas como superiores, como la música o el tejido. En este sentido, tales cosas constituyen por derecho uno de los puntos más importantes de la cultura ordinaria. ${ }^{4}$

Para muchas madres su comida, su sazón, es una forma de consentir al esposo y a los hijos, una manera de tenerlos contentos, de agradarlos, de complacerlos, de ahí que para muchos la comida de casa hecha por la madre, la abuela o la tía, conlleve una serie de significados que tienen que ver con el afecto, con la vida familiar.

\section{CÓMO SE HIZO LA INVESTIGACIÓN}

Este trabajo es el resultado final de un proceso de investigación cualitativa en el transcurso de un año, para ello fue necesario buscar información bibliográfica que hiciera referencia a la cocina como un espacio de producción y reproducción de la vida cotidiana; sin embargo, esta tarea no fue fácil ya que existen pocos materiales que tratan la temática y los existentes son en su mayoría de Estados Unidos o de Europa. Por esto, la contextualización teórica está basada en datos que quizá no hablen lo suficiente de las concepciones y percepciones específicas de México. No obstante, el trabajo de campo que he realizado lo llevé a cabo en un contexto exclusivamente mexicano, específicamente en la región Centro. Para esto abordé aspectos referentes a la alimentación, la cultura, las tradiciones y las costumbres que me permitieran dibujar un contexto con una variedad de elementos necesarios para comprender cómo se estructura la cotidianeidad en las familias, la cocina y el hacer de comer; sus significados e implicaciones; cómo se organizan, estructuran y reestructuran día con día; y cómo se forman, se transmiten y se transforman. Para lograrlo, he utilizado como instrumentos metodológicos, entrevistas a profundidad, alternando con la observación directa de las actividades propias de la cocina.

$4 \quad$ Ibid., p. 154. 
En un principio analicé cinco familias, tres de la ciudad de Aguascalientes y dos de la ciudad de Calvillo, Aguascalientes. Conforme fui avanzando en la investigación, pude percatarme de que las respuestas dadas en las entrevistas no me permitían acercarme lo suficiente a la vida cotidiana, era más fácil obtener información por medio de pláticas menos formales sin la imposición de una grabadora; fue por medio de anécdotas, recetas y consejos que me fue posible obtener valiosa información sobre la manera en que viven la cocina en las familias. Pude percibir que era más fácil obtener conocimientos a través del diálogo, sobre todo entre mujeres en las que por algún motivo la cocina, sus formas de organización y la comida salían a relucir, precisamente, en la cocina. Así, me fijé en otras voces de mujeres y hombres y escuché con atención a quienes sin querer (o más bien sin saberlo) hablaban de aquellas cosas que para mí son tan atractivas e importantes, sobre las formas de organización de la vida cotidiana, la cocina, hacer de comer y alimentarse. Sin embargo, la mayoría de las personas entrevistadas fueron mujeres de entre 45 y 55 años de edad, aunque también hablé con niños y con personas de hasta 81 años.

Por principio podría delimitarse que se tienen tres tipos de población: la de Calvillo, propia de una ciudad chica; la de Aguascalientes de una ciudad media, y la perteneciente a una ciudad grande, Guadalajara. Esto dejó ver diferencias importantes en cuanto a las actividades que realizan, las formas de concebir la cocina y la manera de llevar a cabo la vida cotidiana.

La tabla 1 muestra algunos aspectos generales sobre la población estudiada, conforme se irá avanzando podrán apreciarse otras cuestiones que se refieren a la maneras de producción y reproducción de la vida diaria que no son posibles clasificar u ordenar mediante una tabla.

\section{¿POR OUÉ Y OUÉ COMEMOS?}

¿Por qué necesitamos comer? En primera instancia para satisfacer las necesidades energéticas del organismo, todos los seres humanos debemos someternos a esta necesidad a lo largo de toda nuestra vida; lo que podría distinguirnos unos de otros, es decir, nuestras prácticas alimenticias, sería en palabras de Luce Giard: 
TABLA 1

\begin{tabular}{|c|c|c|c|c|}
\hline Lugar & $\begin{array}{l}\text { No. de } \\
\text { miembros por } \\
\text { familia }\end{array}$ & $\begin{array}{l}\text { Quién sustenta } \\
\text { a la familia } \\
\text { económicamente } \\
\text { económicamente }\end{array}$ & $\begin{array}{l}\text { Actividades del } \\
\text { padre }\end{array}$ & $\begin{array}{c}\text { Actividades de la } \\
\text { madre }\end{array}$ \\
\hline Calvillo & 7 & El padre & Profesor & Hogar \\
\hline Calvillo & 5 & Ambos & Profesor & $\begin{array}{l}\text { Hogar y } \\
\text { Costurera }\end{array}$ \\
\hline Cd. Aguas. & 4 & El padre & Mecánico & Hogar \\
\hline Cd. Aguas. & 4 & La madre & Abogado & Médico y hogar \\
\hline Cd. Aguas. & 6 & La madre e hijos & Músico & $\begin{array}{c}\text { Comerciante y } \\
\text { hogar }\end{array}$ \\
\hline Guadalajara & 6 & Ambos & Ing. Civil & $\begin{array}{c}\text { Prefecta, } \\
\text { Homeópata y } \\
\text { hogar }\end{array}$ \\
\hline Guadalajara & 5 & Ambos & Profesor & $\begin{array}{c}\text { Profesora y } \\
\text { hogar }\end{array}$ \\
\hline Guadalajara & 5 & Ambos & $\begin{array}{l}\text { Supervisor de } \\
\text { zona escolar y } \\
\text { Homeópata }\end{array}$ & $\begin{array}{l}\text { Dir. de esc. } \\
\text { primaria y } \\
\text { hogar }\end{array}$ \\
\hline
\end{tabular}

Los periodos de abstinencia voluntaria como medida de economía en tiempos de penuria que pueden llegar hasta la observancia de un riguroso y prolongado ayuno (El Ramadán del Islam, los ritos de purificación iniciática de los africanos por ejemplo), las múltiples dietas para adelgazar que pueden privar de comer ciertos alimentos ó recomendar sólo el consumo de algunos o hasta el rechazo obstinado de todo alimento (por conductas anoréxicas, huelga de hambre asumida por voluntad política), etc. ${ }^{5}$

Sin embargo, el consumo cotidiano de alimentos no es indiferenciado tanto en calidad como en cantidad, ya que debe cubrir imperativos

5 Michel de Certau, Luce Girad y Pierre Mayol, op. cit., p. 168. 
tales como su composición, proporciones, nutrientes, etc.; además, variará en cuanto a necesidades individuales tales como peso, estatura, edad, género, etapas de vida, intensidad de actividades, etc. y también en cuanto a condiciones climáticas, geografía, economía, etc.

Comemos lo que podemos "ofrecernos", o lo que nos gusta. Según Luce Girad, el término "poder" remite aquí a lo disponible como suministros, a lo accesible como precio, a lo asimilable mediante la digestión, a lo autorizado por la cultura, a lo que valora la organización social. "Gustar" es del todo confuso, ligado al juego múltiple de los atractivos y de las aversiones, fundado en las costumbres de la infancia magnificadas por el recuerdo o tomadas al revés por la voluntad adulta de perder el apego.

En general, comemos lo que tradicionalmente los padres nos enseñaron a comer, de la misma manera que a ellos les fue enseñado. Nos gusta lo que les gustaba, lo dulce o lo salado; entonces, lo más indicado es creer que comemos nuestros recuerdos, los más seguros, los más sazonados de ternura y ritos que marcaron nuestra primera infancia. ${ }^{6}$

En una de las entrevistas realizadas a la señora E (Calvillo), al preguntarle sobre cuáles eran las comidas que ella preparaba cotidianamente, ella se remite a su madre diciendo: "Yo pienso que las comidas que me enseñé con mi mamá son las que yo hago, aunque las he ido modificando según los gustos de mis hijos y de mi esposo."

Comer no sólo sirve para conservar la maquinaria biológica del cuerpo, sino para concretar una de las maneras de relación entre persona y mundo, al perfilar así una serie de marcas fundamentales en el ámbito espacio-temporal, en donde el alimento se convierte entonces, en un verdadero discurso del pasado y el relato nostálgico del país, la región, la ciudad o el pueblo donde se nació.

A lo largo de casi toda la historia, los seres humanos han dependido de los productos cultivados en la localidad. Aunque en los países desarrollados se tiene hoy la oportunidad de comer casi todo lo que se quiere y cuando se quiere, la población sigue mostrando dietas que

$6 \quad$ IGid., p. 189.

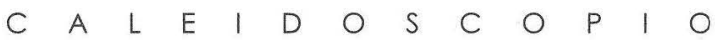


reflejan su tradición local. Así, en el norte de Europa y en los Estados Unidos, donde abundan las gramíneas y los granos (excelentes para criar animales), los alimentos más populares siguen siendo los lácteos, ternera, cordero, el pan y la cerveza, aunque es posible que las personas que tienen poco tiempo o pocas habilidades culinarias prefieran ciertos tipos de alimentos procesados o precocinados. En contraste, el vino de la región, la fruta, el aceite de oliva y la pasta siguen teniendo un consumo mayoritario en el sur de Europa. En Latinoamérica, el maíz y el frijol son los dos alimentos básicos de la población. En gran parte de Asia, el arroz sigue siendo la base de la dieta, donde proporciona el $90 \%$ de las calorías de la población, al igual que en Japón, Singapur y Hong Kong. No obstante, algunos alimentos importados se consumen universalmente en casi todo el mundo, como la patata o papa, el café y los tomates. En las comunidades multiculturales cada grupo étnico tiende a conservar sus tradiciones alimenticias, pero hay una gran variedad de alimentos procedentes de todo el mundo que hoy están disponibles y forman parte de la dieta normal en muchos países. ${ }^{7}$

Toda práctica alimentaria depende en línea recta de una red de impulsos (atracción y disgusto) respecto a los olores, colores y formas, y también por lo que hace a los tipos de consistencia; esta geografía se halla tan fuertemente culturizada como las representaciones de la salud y de la buena conducta en la mesa. Al término de estas exclusiones y selecciones, el alimento retenido, autorizado, preferido es el lugar de apilamiento silencioso de toda una estratificación de órdenes y contraórdenes que dependen al mismo tiempo de una etnohistoria, una biología, una climatología, una economía regional, de una invención cultural y de una experiencia personal. Su selección depende de una suma de factores positivos y negativos, ellos mismos dependientes de determinaciones objetivas de tiempo y lugar, de la diversidad creadora de los grupos humanos y las personas, de la contingencia indescifrable de las microhistorias. ${ }^{8}$

7 Miriam Lowenberg et. al. Los alimentos y el hombre, México, Limusa-Wiley, México 1970 , p. 415.

8 Tomado de: Michel de Certau, Luce Girad y Pierre Mayol, en op. cit., pp. 189-191. 
El inventario de ingredientes, de sus asociaciones y de sus transformaciones en diversas preparaciones, proporciona los elementos de una inmensa combinatoria de múltiples entradas, a la que hay que renunciar para establecer un repertorio de manera unívoca por cien razones: las especies animales y vegetales viajan y se modifican en calidad según sus condiciones de producción; los sabores no se cuantifican y difícilmente se distinguen, siendo esto así "todos los placeres del paladar están sometidos por partida doble a las leyes de la oralidad: como absorción de alimento, placer de engullir, y como apoyo de una actividad ligüística profusa, placer de hablar, que describe, nombra, distingue, matiza, compara, colorea y desdobla." ${ }^{9}$

\section{Cultura DE LA ALimEnTACión}

Clifford Geertz define la cultura como una pauta de significados, como el conjunto complejo de signos, símbolos, normas, modelos, actitudes, valores y mentalidades a partir de los cuales los actores sociales confieren sentido a su entorno y construyen, entre otras cosas, la identidad colectiva de un grupo, lo cual permite: distinguir dos estados o modos de existencia de la cultura: el estado objetivado, en forma de objetos, instituciones y prácticas directamente observables, y el estado subjetivado, o internalizado, en forma de representaciones sociales y habitus distintivos e identificadores que sirven como esquemas de percepción de la realidad y como guías de orientación de la acción"10

La cultura de la alimentación abarca muchos aspectos que inician con la necesidad de comer y dado que ésta se delimita de acuerdo al espacio físico y geográfico, van marcando los elementos con los que cuenta el ser humano para subsistir; asimismo, los recursos económicos y la tecnología marcarán los hábitos y formas de alimentación. A partir de lo anterior, se van generado otras cuestiones: cuando ya está

9 Ibid., p. 192.

10 Gilberto Giménez, "Cultura, territorio y migraciones. Aproximaciones teóricas", en Alteridades, núm. 11, México, 2001, p. 11. 
satisfecha la primera necesidad, que es comer, el individuo comienza por elegir aquellos alimentos que le son más apetecibles o agradables, de aquí que exista gran diversidad de alimentos y la manera en que se consuman y cómo se preparen dependerá de cada cultura, sus ideas, sus creencias y su religión.

Las diferencias humanas, sociales y culturales pueden llevar a repudiar o sentir asco por aquellas cosas que otros grupos sociales consumen; es preciso evitar las connotaciones peyorativas, escabrosas, anticuadas o incluso de inconcebibles; hay que tratar de asimilar que existen concepciones distintas, y que ninguna de ellas es mejor que otra. Asimismo, todos necesitamos de instrumentos o utensilios para preparar los alimentos, dependerá por supuesto de los recursos y de la cultura del grupo social al que se pertenezca cuáles empleemos y cómo, la forma en que comemos, cómo nos sentamos a comer, si comemos acompañados o solos, etcétera. Por todo esto, a partir de la alimentación, los hábitos, las costumbres y los usos que le damos a la comida, podemos deducir y descubrir aspectos sobre porqué somos y actuamos de tal o cual manera.

Las costumbres y los estilos alimenticios difieren de un grupo humano a otro. Se entenderá por hábitos alimenticios las costumbres de una comunidad que refleja la forma en que su cultura traza la norma de conducta de los individuos del conjunto en relación con el alimento, de donde resulta que el grupo acaba por tener un patrón dietético común. Las costumbres alimenticias dependen de una combinación entre tradición, factores psíquicos y bioquímicos. Dentro de ciertos límites, es evidente que las personas comen y prefieren lo que les gusta y consideran que le hace provecho. Los patrones alimenticios se basan en los conocimientos sobre la materia y, al menos, en parte, en los países modernos y de gran desarrollo técnico, en la propaganda comercial. ${ }^{11}$

Los factores que rigen la dieta de las personas pueden clasificarse de la siguiente forma:

11 Tomado de Lowenberg, op. cit., pp. 97-98. 
- El ser humano come lo que puede encontrar a su alrededor.

- Cuando puede elegir, escoge lo que sus antepasados comieron antes que él.

- Se determina de acuerdo a circunstancias, gustos, conocimientos y cuestiones culturales.

Es importante destacar que lo que se come debe de estar en relación con las necesidades fisiológicas del cuerpo, pues de lo contrario, el conglomerado humano no podría sobrevivir, provocándole un desequilibrio orgánico.

La elección entre diversos alimentos puede hacerse cuando éstos son suficientemente abundantes como para permitirla; todos y todas sabemos que en épocas de hambre se toleran alimentos vedados y se relajan muchas restricciones, incluso se sabe de actos de canibalismo en los anales de la historia, de los primeros pobladores de estas tierras cuando el hambre los amenazaba de muerte.

Las prácticas alimenticias varían entre los grupos sociales, ya que cada uno de ellos, y de acuerdo a su propia historia, va creando un sistema complejo de normas de conducta. Los individuos situados dentro de determinadas culturas, responden a presiones de la conducta sancionada por su sociedad, eligiendo, consumiendo y utilizando los alimentos puestos a su disposición. Por ello, puede decirse que los usos alimenticios de un conjunto humano son, el producto del ambiente actual del grupo y de su historia pasada. Estos hábitos y costumbres que se han vuelto significativos para el grupo, se conservan celosamente y no cambian con facilidad. Sin embargo, los hábitos alimenticios que no tienen un sentido profundo para la comunidad, suelen cambiarse con relativa disposición.

Los grupos étnicos tienen buen cuidado de instruir a los niños sobre sus estilos nutritivos a fin de que los pequeños sepan lo que se considera como alimento y lo que no se considera como tal. El niño africano de las tribus primitivas, por ejemplo, aprende a estimar los saltamontes y las raíces, lo mismo que el norteamericano aprende a beber leche. También a los niños se les instruye la conducta sancionada por la sociedad en relación con los alimentos, de esa manera, llegan a conocer los límites que les enseñan a rehusar ciertos alimentos, de manera que los impulsos infantiles originales, inclinados a la satisfacción

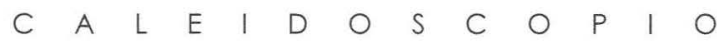


del hambre, se convierten en apetitos socialmente aceptables. ${ }^{12}$

La atención directa de la madre es otro factor que ejerce una influencia importante en las costumbres alimenticias de los hijos, incluso se valdrá de algunos procedimientos ingeniosos o de algún engaño para inducir a los hijos a comer lo que considera provechoso para ellos, aún cuando a ella pueda parecerle desagradarle. Pero aún dentro de un mismo grupo, no todos comen lo mismo, se van formando subgrupos.

Sociólogos y antropólogos han observado que en culturas primitivas, el cultivo y la recolección de alimentos suelen ser actividades comunitarias: el orgullo y la satisfacción de haber producido alimento se convierten en fuerzas que estrechan los vínculos del grupo. Cada individuo coopera y da paso a las preferencias comunes que son aceptables desde un punto de vista cultural. En estos grupos, el compartir la comida, acaba por crear una especie de parentesco, aun fuera de las relaciones familiares de consanguinidad. La tendencia de una sociedad a tener zonas culturales con grupos de individuos que conservan sus costumbres alimenticias es quizá mayor en pueblos donde las comunicaciones de un lado a otro del país no están muy desarrolladas. En las grandes ciudades, los grupos activos procedentes de culturas totalmente distintas, pueden ejercer una influencia poderosa que favorezca los cambios, y por lo tanto, ser verdadera causa de éstos en materia alimenticia. En muchas culturas comer se considera una actividad privada, de la que ha de disfrutarse dentro de los límites familiares; se sabe de lugares en donde cada individuo come aparte de todos los demás, aunque sean miembros de la familia. Por ejemplo, en Melanesia y Polinesia, el marido y mujer viven separados y tienen distintos alojamientos, comidas, trabajos y propiedades, ahí la regla es que el hombre no debe ver comer a la mujer, ni ésta al hombre. Entre los semitas, el hombre no acostumbra comer con su mujer y los hijos en Arabia septentrional, ninguna mujer come antes que los varones, y nadie debe ver comer a nadie. ${ }^{13}$

12 Marvin Harris, Bueno para comer, Enigmas de alimentación y cultura, Alianza (Col. Los noventa), México, 1989, p. 103.

13 Tomado de Lowenberg, op .cit., pp. 107-108. 
Cuando los alimentos son suficientes para elegir (o a veces no), surge una serie de hábitos y estilos alimenticios con sus concomitantes tabúes y prejuicios que nos hablan de toda una cultura alimentaria. Desde una óptica científica, los seres humanos somos omnívoros, es decir, criaturas que comen alimentos de origen animal y vegetal; satisfacemos las necesidades de nuestra nutrición consumiendo una gran variedad de sustancias, comiendo y digiriendo toda clase de cosas. Pero en realidad, el inventario dietético de la mayoría de los grupos humanos parece bastante reducido, pues dejamos pasar algunos productos por considerarlos inadecuados para que nuestra especie los consuma. Por ejemplo, los hindúes no comen carne de vacuno, los judíos y los musulmanes no comen carne de cerdo y los norteamericanos no comen guisado de perro.

Ese dejar pasar algunos productos, evidentemente, responde a las tradiciones gastronómicas de cada pueblo, su cultura alimentaria, y por lo tanto, "en cuestión de gustos, no hay nada escrito": la carne de caballo les gusta a los franceses y a los belgas, la mayoría de los pueblos mediterráneos son aficionados a la carne de cabra; larvas y saltamontes son manjares apreciados en muchísimos sitios, y según algunos informes del ejército estadounidense, en cuarenta y dos sociedades distintas personas comen ratas; los antiguos romanos se encogían de hombros ante la diversidad de tradiciones alimentarias que coexistían en su vasto imperio y sin embargo seguían fieles a sus salsas preferidas a base de pescado podrido. ${ }^{14}$

La idea de que los hábitos alimenticios son arbitrarios se ve reforzada por la existencia de preferencias y limitaciones desconcertantes que casi todo el mundo considera poco prácticas, irracionales, inútiles e incluso nocivas. Desde un punto de vista antropológico y/o cultural, este relativismo en materia de gustos culinarios, no se debe ridicularizar ni condenar, por el simple hecho de ser diferentes a los nuestros. La comida debe alimentar la mente colectiva, antes de poder pasar a un estómago vacío; en la medida en que sea posible explicar las prefe-

14 Harris, op cit., p. 11. 
rencias y aversiones dietéticas, la explicación habrá de buscarse no en la índole de los productos alimenticios, sino más bien en la estructura de pensamientos subyacentes al pueblo del que se trate.

Diversas disciplinas sociales han documentado ampliamente las maneras en que la alimentación revela y preserva las costumbres de los pueblos y regiones del mundo, localizándolas además, en sus respectivas culturas, forjando una visión territorializada de la cultura y de la comida. En antropología, la cultura se define internamente por la existencia de una matriz significativa y significadora, que tendría la capacidad de reinterpretar los elementos extranjeros (la premisa de una oposición entre lo interno y lo externo) así, ambas premisas estarían presentes en los fenómenos más característicos del acontecer cultural de los pueblos (sincretismo, aculturación, difusión y tradición cultural).

A diferencia de otros aspectos de la cultura, la alimentación es un ámbito donde resulta más fuerte la inercia de las costumbres sobre las prácticas y creencias de las sociedades. De este modo resulta importante reconocer el peso de las tradiciones gastronómicas involucradas en los procesos culturales de transmisión colectiva de gustos alimentarios diferenciados y compartidos.

Es necesario reconocer que la alimentación exhibe a plenitud los condicionamientos propios de las interacciones microsociales de las familias. Esto ocurre así en la medida en que el abastecimiento y la producción de la comida forma parte sustancial del trabajo doméstico realizado fundamentalmente por mujeres como una tarea que tradicionalmente se le ha designado, ésta debería reconocerse por ser una labor de reproducción social. ${ }^{15}$

INFLUENCIAS ÉTNICAS

Los grupos sociales tienden a formar sus propios hábitos alimenticios, la actitud hacia los alimentos varía de unos a otros, desde la indiferencia

15 David Osaguera Parra, "El Fast-food y el apresuramiento alimentario en México", en Estudios sobre las culturas contemporáneas, Revista de investigación, vol. II, núm. 3, México, junio de 1996, p. 112. 
hasta el excesivo interés. La estima por el alimento y su capacidad de responder satisfactoriamente a algún factor emotivo, varían de un grupo étnico a otro, por ejemplo, los franceses vislumbran la comida con gran respeto y tienen merecida fama por su cocina; para los italianos es un placer comer, y hacerlo en familia. En otros grupos culturales y ciertas familias, comer no es más que un deber. En unos grupos más que en otros, las mujeres son famosas por ser afectas ya sea a la cocina - a la comunidad, cuando cambian de casa, tratan de establecerse en las cercanías de lugares donde haya personas con antecedentes étnicos similares, o costumbres semejantes.

Se dice que el modo de cocinar revela la cultura de un país, y que el alma de una nación refleja su alimento. Por ejemplo, que el alimento de los japoneses refleja su amor al orden y a la limpieza, como lo demuestra el arreglo exquisitamente nítido y bien cortado de la comida para el sukiyaki. También se piensa que los platillos nacionales británicos revelan su aséptica robustez y reserva, mientras que la sutileza de expresión galesa se pone de manifiesto en sus delicadas salsas que los italianos, afectos a la tierra lo demuestran en sus pastas. ${ }^{16}$

Es importante aclarar que los gustos y reacciones individuales con respecto a los alimentos quedan comprendidos entre las clases de "comestibles para individuos como yo", y comestibles para mí mismo", una persona puede comer hígado, pero otra lo encuentra imposible de ingerir. La razón puede ser que cada cual, individualmente, percibe su sabor de manera distinta y reacciona en forma diferente a su consistencia. ${ }^{17}$

Pero también comemos nuestras representaciones sociales es decir, lo que suponemos bueno para nosotros, según el comité de Hábitos Alimenticios del Consejo Nacional de Investigación de los Estados Unidos, pueden clasificarse los artículos comestibles en los siguientes: como no comestibles, comestibles para animales, comestibles para el ser humano pero no en mi calidad de ser humano, comestible para el ser humano como

Tomado de Lowenberg, op. cit., 325.

17 Ibidem.

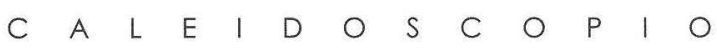


tal, y finalmente comestible para mí personalmente. Estas clasificaciones están ulteriormente reforzadas por las diferentes actitudes: los artículos que no se comen crean impurezas, comerlos es una inmoralidad, son denigrantes, perjudican la posición de la persona, etc.

Es importante conocer los alimentos que una comunidad considera comestibles. Por ejemplo, cuando se introdujo una nueva especie híbrida de maíz en una comunidad hispanoamericana, a pesar de que el rendimiento de las cosechas era tres veces mayor que el del maíz común, en menos de un lustro aquella gente dejó de cultivarlo, porque quienes se hacían cargo de hacer la comida no les satisfacía la consistencia de las tortillas y a nadie le gustaba el sabor. Lo mismo pasó en la India, cuando el pueblo rechazó el trigo porque no era blanco como el arroz que acostumbran. En Estados Unidos se presentaron muchas quejas por el color gris del pan elaborado con extracciones más nutritivas y económicas de la harina de trigo usada durante la conservación de este grano en tiempo de guerra. Sin embargo, de todos los cereales, el trigo es el más adecuado, completo y nutritivo. Muchas personas en todo el mundo, tienen la impresión de que un alimento es más deseable cuanto más claro es su color. El pan blanco empezó a venderse en Francia en 1820 y durante muchos años fue considerado como un artículo de lujo. ${ }^{18}$

\section{¿QuÉ SIGNIFICA LA COCINA?}

La cocina puede ser el lugar bendito de una dulce intimidad, charlas deshilvanadas, seguidas a medias palabras con la madre que da vueltas de la mesa al fregadero, con los dedos ocupados, pero con el ánimo dispuesto y la palabra atenta para explicar, discutir, reconfortar. Más tarde, artista él mismo en su cocina o visitante de la del prójimo, el adulto suspira: "me produce tanto placer entrar a la cocina. Cada vez que entro tengo la impresión de volver a entrar a mi infancia". ${ }^{19}$

De acuerdo con las entrevistas realizadas, la cocina representa un lugar fundamental dentro de la casa, ya que es ahí en donde se pasa

\footnotetext{
18 RIUS, La panza es primero!, Posada, México, 1991, p. 78.

19 De Certau, Girad y Mayol, op. cit., p. 197.
} 
un buen tiempo preparando los alimentos, es uno de los lugares de mayor convivencia porque es ahí en donde se reúnen a platicar, en algunos casos aunque no coman todos juntos. Además, para las mujeres la comida puede ser una forma de demostrar amor por sus familias, al consentirlos, prepararles lo que les gusta en sus cumpleaños, buscando consciente o inconscientemente, al mismo tiempo el reconocimiento por su labor, su dedicación y su esmero.

Las mujeres entrevistadas comentaron con frecuencia que la cocina es un lugar agradable y cómodo, bonito y que así debe ser ya que son ellas, tradicionalmente, quienes se ocupan mayoritariamente de este espacio. Reportaron ser ellas las que deciden qué comer, a qué hora, qué platillo según la ocasión; ellas también se encargan de administrar el presupuesto designado para estos fines y de organizarse de acuerdo a sus actividades y las de los miembros de la familia.

En contraste, los hombres entrevistados se refieren a la cocina como un espacio necesario y funcional dentro de cada una de las casas; en sus respuestas realizan una descripción más o menos detallada de las cosas que hay y para qué sirven en la cocina, también aseguran que su participación en ella no es constante, ni prioritaria y que tampoco se involucran en lo que habrán de comer cada día; cabe destacar que para algunos de los entrevistados, al mencionar la cocina, inmediatamente la relacionan con la mujer, ya sea la madre o la esposa, en donde puede encontrársele y por ello es agradable.

El señor A (Calvillo) menciona: "La cocina es el lugar en donde la mujer encarga de preparar los alimentos que habremos de consumir todos los días."

El señor E (Ciudad de Aguascalientes) decía: "Mi cocina fue muy alegre casi siempre, porque antes sí entraba más la mujer a la cocina pero ahora ya no entra tanto, ahora como que se ve más tristona... tristona o.. ( la esposa se molesta por el comentario y lo ve de reojo) pero en sí es muy cómoda tiene, pues, todos los aditamentos..."

Al preguntarles sobre la manera en que participan dentro de la cocina, los varones adultos entrevistados en su totalidad mencionaron, inequívocamente, que se comían lo que hacía su mujer; algunos otros hicieron referencia a que la acompañaban a las compras, sin intervenir o tomar decisiones sobre lo que habría de comprarse o cocinarse: 
En algunas ocasiones yo la acompaño y le ayudo a cargar el mandado, pero ella es quien sabe lo que hace falta... antes yo iba algunas veces a comprar el mandado, pero ella siempre renegaba de que no escogía bien las verduras, que compraba cosas que no hacían falta y así... ella es quien va y algunas veces yo la acompaño..(Señor E. Ciudad de Aguascalientes).

Algunos hablaron de que en ocasiones son ellos mismos quienes se preparan sus alimentos cuando se encuentran solos o no hay nadie más que pudiera hacerlo por ellos.

Los hombres jóvenes, la mayoría hijos que viven con sus padres, narraron cómo desde muy pequeños la madre les ha encomendado la tarea de comprar lo que haga falta en el momento:

Desde que yo me acuerdo mi mamá siempre, llegando de la escuela me decía: iÁndale ve por las toritillas que ya es tarde! (S. Ciudad de Aguascalientes).

Yo siempre voy a la tienda a comprar lo que le hace falta a mi mamá a la hora de la comida, a veces me manda muchas veces; si voy a comprar jitomates, apenas oye que abro la puerta y me dice: ay mijo! tráeme cebollas que ya se me acabaron... (C. Calvillo).

Es importante mencionar que sólo algunos entrevistados afirmaron participar o ayudar esporádicamente en estas labores, argumentando que normalmente quien lleva esta tarea es la mujer o las mujeres de la familia.

Realizando una comparación entre géneros en cuanto al desenvolvimiento y extensión de las respuestas dadas, resultó bastante notorio que los varones, tanto jóvenes como adultos, se remitían a cuestiones puramente descriptivas y funcionales de manera específica, a diferencia de las mujeres quienes se extendían ampliamente sobre esta temática. Quizás esto pueda deberse a que las percepciones sobre la cocina no son las mismas, el referente es distinto, el significado que le otorgan no es igual, posiblemente sea por la cercanía que las mujeres pudieran tener con este espacio.

\section{HACER DE COMER}

La preparación de una comida proporciona esa rara felicidad según Girad, de producir uno mismo cualquier cosa, de labrar un fragmento 
de lo real, de conocer las alegrías de una miniaturización demiúrgica, al asegurarse el reconocimiento de quienes la consumirán por medio de inocentes y agradables seducciones. Este trabajo culinario que se supone sin misterio ni grandeza, se despliega en un complejo montaje de cosas que hacer, de acuerdo con una secuencia cronológica predeterminada: prever, organizar y proveerse; preparar y servir; levantar la mesa, guardar y limpiar. Las labores culinarias se encuentran en su oscura realidad. Labor tradicionalmente de mujeres sin horario ni salario (salvo el estar al servicio del prójimo y de los hijos), trabajo sin valor agregado ni rendimiento (los hombres calculan las cosas serias), labor en que el éxito siempre se prueba con la privación del momento, sí lento, interminable trabajo de mujeres. Mujeres muy pacientes que repiten infinitamente las mismas acciones. ${ }^{20}$

Un día comentando entre familia lo bien que cocinaba mi abuela, mi mamá dijo: "Tu abuelita hace la comida con todo el tiempo del mundo, le dedica mucho tiempo, por eso todo le queda rico, yo siempre ando a las carreras..."

Tradicionalmente son las mujeres quienes pelan las papas, las zanahorias, los pepinos, las naranjas, etc., para ellas no se trata de un quehacer complicado. Se enseña desde los primeros años, habitualmente de madre a hija: "Ven a ayudarme a pelar las papas para la comida, hija".

Una entrevistada hablaba de que su mamá le llamaba por teléfono desde su trabajo, casi todos los días, cuando pensaba que ya había llegado de la escuela, y le pedía que adelantara algunas cosas para la comida, tales como hacer el agua fresca, o pelar las papas o los chayotes, según lo que fueran a comer (I. Ciudad de Aguascalientes)

Las mujeres pelan frutas y verduras día a día a veces varias veces en uno mismo, las verduras son un problema de mujeres, el dominio de las mujeres es el de la mesa, el de la comida, el de las verduras, que son las menos caras, de lo que se habla poco, pero que se pelan y arreglan de mil maneras, y que diario se preguntan ¿cómo las voy a

20 Ibidem. 
preparar mañana? esto sí representa un problema doméstico; y al día siguiente, pelan de nuevo, verdura tras verdura; pican y vuelven a picar pacientemente en pequeños trozos, minuciosos, todos parejos, para que todo esté bueno y, también bonito, bien presentado. Presentable para que se antoje.

En una ocasión mi tía F (Guadalajara) vino a visitar a mis padres; al día siguiente, al estar haciendo la comida, mi tía dijo: "para la ensalada hay que picar todo muy finito, así se les antoja más, hay que acomodar todas las verduras de modo que se vean más bonitas, iah! entre más colores mejor, como dicen ¿no? de la vista nace el amor..."

Hacer de comer implica sucesión de acciones y de pasos, repetidos y obligados. Luce Girad hace una distinción entre dentro y fuera. Dentro: preparar en la cocina; de la cocina al comedor para servir y comer, levantarse sin cesar para correr a vigilar los guisados sobre el fuego o traer la salsa que hace falta en la mesa; del comedor a la cocina, para levantar la mesa; de nuevo en la cocina para lavar, acomodar... Fuera: de la cocina al mercado, a la tienda de abarrotes, a la tortillería, a la carnicería, a la frutería; luego de regreso a casa, con los brazos cargados de bolsas llenas... Dentro: en la cocina, vaciar las bolsas; acomodar los productos, meter al refrigerador lo que sea propio, hacer cuentas, revisar el cambio y las notas. Sentarse, por fin. Hoy, mañana y pasado, recomenzar el mismo eslabonamiento, desengranar la misma letanía de preguntas: ¿qué queda para esta noche? ¿̇uántos seremos en la mesa?, y mañana, ¿qué hacer de almorzar?21

Deacuerdo con las respuestas de algunas entrevistadas, ellas hacían mención a lo difícil que es saber qué se hará de comer ese día, o el siguiente...

La pregunta de todos los días ćqué voy a hacer de comer?, hacerlo es fácil, pero saber qué, sí me cuesta trabajo.... (Señora C. Ciudad de Aguascalientes).

Cuando le pregunto a mi esposo qué hago para la comida, él me dice: Lo que sea, lo que tu quieras, tú piensa, tú eres la mamá... eso me enoja, creo que el también podría ayudarme pensar, a veces no se me ocurre nada... (Señora G. Ciudad de Aguascalientes).

21 Tomado de: De Certau, Girad y Mayol, op. cit., p. 206. 
En muchas ocasiones queda bastante comida como para volver a comerla al día siguiente, lo cual no les agrada mucho a los demás miembros de la familia. Sin embargo, la mayoría de las mujeres entrevistadas comentaban que esta comida no habría de desperdiciarse, ya que lo consideraban "casi como pecado". Por eso, en muchos casos las mujeres reinventan ese platillo ya hecho para que luzca diferente, tanto en apariencia como en sabor. Lo interesante es que, aún ellas mismas, no le otorgan el mismo valor que si hubiera sido algo recién elaborado.

Cuando el señor A (Calvillo) le pregunta a su esposa si había frijoles, ésta le dice: "pues si quieres hay de ayer, él le contesta: iah no, entonces no!..."

\section{LA RUTINA}

Luce Girad menciona que es digno aceptar las actividades culinarias, como objeto de interés, análisis y registro estas prácticas ordinarias consideradas insignificantes; aprender a mirar estas maneras de hacer furtivas y modestas, que a menudo son el único lugar de inventiva posible del sujeto: invenciones precarias sin nada que las consolide, sin lengua que las articule, sin reconocimiento que las eleve; chapuzas sometidas a la pesadez de las limitaciones económicas, inscritas en la red de las determinaciones concretas. En este nivel de invisibilidad social, en este grado de no reconocimiento cultural, correspondió desde hace mucho y corresponde todavía, como por derecho, un lugar para las mujeres, pues a sus ocupaciones cotidianas no se presta en general atención alguna: es necesario que se hagan "esas cosas"; es necesario que alguien se encargue de eso; de preferencia será una mujer, antaño era una mujer "buena para todo", cuya apelación expresaba de lo mejor su condición y su función. Trabajos sin término visible, nunca susceptibles de recibir un último toque: el cuidado de los bienes del hogar, el mantenimiento del conjunto de la familia parecen caer fuera del campo de una productividad digna de evaluación; sólo su ausencia arranca una seña de interés, pero es entonces de reprobación. ${ }^{22}$

22 Ibid., p. 158. 
Como todo el actuar humano, estas labores tradicionalmente femeninas son muestra del orden cultural de una sociedad a otra, de su jerarquía interna, de las diferentes maneras de proceder; pero también de una generación a otra y de una clase social a otra, en una misma sociedad, las técnicas que gobiernan así como las reglas de acción y los modelos de comportamiento que se tocan, se transforman. Puede crearse un estilo propio, según acentúe el elemento de la práctica, se dedique a tal otra, inventa una manera personal de seguir su itinerario mediante lo recibido, lo admitido y lo ya hecho. Así, al hacerse de habilidades comunes se da finalmente una manera propia de poner en movimiento las secuencias cronológicas unas después de otras y componer sobre temas obligados, como una música de variaciones nunca fijadas en forma estable.

"Las prácticas culinarias se sitúan en el nivel más elemental de la vida cotidiana, en el nivel más necesario y más menospreciado..."23

Hacer la comida día tras día, representa el sostén de una práctica elemental, humilde, obstinada repetida en el tiempo y en el espacio, arraigada en el tejido de las relaciones con los otros y consigo misma, marcada por la novela familiar y la historia de cada una solidaria tanto con los recuerdos de la infancia como con los ritmos y las estaciones. "Trabajo de mujeres que las hace proliferar en árboles de acciones, en diosas de Shiva de cien brazos, hábiles, ahorradoras: el ir y venir agitado y rápido para hacer el merengue, las manos que amasan lentamente con un movimiento simétrico, con una especie de ternura continua" 24

Preocupación de quien cocina: ¿la pasta estará bastante suave? Observación: estos jitomates no están jugosos; hay que remojarlos antes de cocerlos, Transmisión de conocimientos: mi madre, tía o abuela siempre me recomendaba agregar una gota de vinagre a las costillas de cerdo a la parrilla. Eslabonamiento de habilidades manuales, que hay que ver hacer para luego poder imitarlas, actividades multiformes

23 Ibidem.

24 Ibid., p. 160. 
muy simples o muy bobas, salvo en los raros casos en que se la eleva a la excelencia, al refinamiento extremo, pero entonces es un asunto de los grandes chef, que son hombres, claro está. ${ }^{25}$

Si con esto no es suficiente, es necesario calcular los tiempos de preparación y cocción, intercalar las secuencias entre sí, componer la sucesión de platos para esperar el calor deseado en el momento preciso; los sentidos también intervienen: más que la información teórica plasmada en una receta, es el olor salido del horno lo que informa respecto a la evolución del cocimiento y sobre la utilidad de aumentar el calor. La ingeniosidad creadora de astucias encuentra ahí su lugar: ¿cómo arreglar los restos de modo que pueda hacerse creer que se trata de un platillo diferente? Cada comida exige la invención de una miniestrategia de repuesto, es decir, cuando hace falta algún ingrediente o algún utensilio, o cuando llegan amigos inesperados a la hora de la comida, hay que saber improvisar sin partitura, ejercer sus capacidades combinatorias. En una ocasión que entrevisté a los miembros de la familia C. A. (Ciudad de Aguascalientes) iba acompañada de otras dos compañeras, la familia acababa de comer, nosotras aún no lo hacíamos; después de saludar, la señora nos ofreció de comer, aceptamos y, después de un rato, la señora nos llamó a la cocina, había preparado unos burritos. Al terminar de comer y en agradecimiento, limpiamos la cocina; en ese momento nos dimos cuenta de que de lo que había quedado de la comida y de frijoles que tenía guardados, nos había improvisado los burritos entonces una de mis compañeras comentó:

Las mamás siempre sacan comida quien sabe de donde, siempre andan inventando algo cuando llegan visitas; mi mamá siempre saca cosas quien sabe de donde, que yo ni sabía que ahí estaban; y me he fijado que tu mamá también, como el día que fuimos a visitarte y tu mamá nos preparó fruta con limón y chilito, ibien rico!; o también cuando estábamos en tu casa haciendo el trabajo y llegó tu mamá y nos trajo unas gorditas. . . (A. ciudad de Aguascalientes)

25 I bidem.

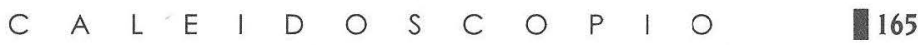


Así, entrar a la cocina y manejar las cosas ordinarias hacen trabajar la inteligencia, una inteligencia sutil, toda llena de matices, hallazgos del momento, una inteligencia viva y ligera que se deja adivinar sin dejarse ver, en pocas palabras una inteligencia muy ordinaria.

\section{DISTINTAS FORMAS DE VIVIR LA COCINA}

Las diferentes formas de prever, anticipar, organizar, de nutrir en sí a la familia, tradicionalmente han sido cuestiones que recaen en la mujer; no obstante sus actividades, sus vidas varían enormemente, algunas se dedican por completo al hogar, otras además trabajan fuera de la casa, algunas estudian. Existe una gran diversidad en las formas de estructurar la vida cotidiana en la familia. Así, la biografía propia de cada mujer, mediará indudablemente la forma de concebir su rol femenino, de esposa, madre, hija, profesionista, trabajadora, etc.

De acuerdo a los diálogos sostenidos con las mujeres entrevistadas, existen diferencias muy marcadas entre las mujeres que se dedican únicamente al hogar y las que trabajan o que tienen otras actividades fuera de casa. Por ejemplo en los casos en el que las mujeres se dedican exclusivamente al ámbito doméstico, se asume completamente el rol de esposa y madre, en el que las hijas tienen igualmente la obligación de involucrarse en la cocina, cocinando día tras día, porque consideran que es su obligación, principalmente para la comida del medio día dedican un "tiempo especial". Para ello, pudiendo preparar aquella receta que le recomendó alguna amiga o que vio en la televisión, o preparar aquel platillo que tanto le gusta al esposo, o quizá darles varios platillos como opción, ya que hay que recordar que no a todos les gusta lo mismo, o tal vez que alguno de los hijos no tolere determinado alimento o si alguna hija está a dieta, etc. Es decir, pudiera pensarse que estas mujeres le brindan más tiempo y dedicación a la cocina, porque consideran que es parte de su función y su obligación como madres y esposas, así como también una forma de agradarlos, de consentirlos, de tenerlos cerca; para la mayoría de estas mujeres implica además un gusto y satisfacción cocinar para sus respectivas familias.

Mi abuela materna me platicó que para ella es un gusto enorme que sus hijos se reúnan en su casa los domingos para comer, porque ya saben que les preparará algo muy rico (como lo que les preparaba 
cuando eran niños): "cuando vienen me siento muy contenta, nunca sobra nada, hasta se andan llevando lo que sobra... iPor mi encantada!"

En el caso de las mujeres que tienen otras ocupaciones, el rol que se asume es distinto, se reconoce que son ellas quienes se hacen cargo de la comida y de ocuparse de la cocina lo hacen únicamente el tiempo necesario, ya que tiene otras prioridades.

De las mujeres entrevistadas que tienen otras actividades, en muchos de los casos, compran la comida en cocinas económicas, les pagan a otras mujeres para que cocinen en sus propias casas, como cocineras, o comen en otros lugares como la casa de su mamá o del esposo, o en establecimientos públicos. Es muy poco común que sean ellas las que hacen de comer.

Entre las pocas mujeres que sí hacen de comer, algunas cocinan todos los días pero lo hacen en las noches o por las mañanas, otras adelantan algunas cosas de lo que harán de comer al día siguiente. La mayoría de ellas cocina los fines de semana, y no es algo agradable para todas o que les proporcione alguna satisfacción.

Mi tía B (Guadalajara) quien trabaja desde muy joven me decía: "Ay no, los fines de semana o cuando son vacaciones, me desespero mucho, todo el día están todos, se la pasan comiendo: Mamá prepáranos que una frutita, que una botanita, nomás se la pasan inventando antojitos."

Cualquiera que sea la forma en que las mujeres deciden organizarse, la responsabilidad de quien se hará cargo de la comida y sus implicaciones recae y se asume generalmente por la mujer; independientemente de sus actividades, son ellas quienes se encargan de este ámbito y de todo lo que conlleva consigo.

En la familia V.L (Ciudad de Aguascalientes), la señora trabaja ocho horas por la mañana y otras cuatro por la tarde, y aún así los demás miembros de la familia esperan a que ella llame por teléfono o llegue de trabajar al medio día para que decida que van a comer. Algunas veces les pide al esposo o a las hijas que compren comida en alguna cocina económica, otras, que adelanten la preparación de algún alimento que ya tiene previamente reservado en el refrigerador, dando instrucciones detalladas y precisas de cómo habrá de prepararse, y en otras, en el momento en que llega decide si comprará algo ya hecho o saldrán a comer por ahí. Cuando le pregunté cómo se organizaba, me respondió: 
No pues soy la principal, la mayor parte del rato que le dedico a la cocina, no es todo el día, la verdad no, yo nunca había estado todo el día en la cocina porque yo siempre como profesionista que soy, siempre he desempeñado mi profesión, siempre. Entonces estoy en la cocina yo creo como unas...2, 3 horas a la hora de la comida, en el desayuno será como una hora y media y en la cena otro tanto otra hora y media... Siempre hemos procurado que nuestra alimentación pues sea equilibrada, como médico que soy, que tenga todos los nutrientes que los conocimientos que tengo me permiten saber qué es lo que necesita nuestro organismo para estar sanos, entonces cotidianamente, el desayuno por lo general pues es fruta, jugo, yogurt, quesadillas, y frijoles o huevo en diferentes variedades, con jamón o... ese tipo de cosas, café con leche o leche o chocolate, atole a veces, pero lo que más consumimos es la leche y el café con leche (Sra. F. ciudad de Aguascalientes).

De acuerdo con las entrevistas y a lo que pude observar en varias de mis visitas a las casas de las diferentes familias, la cocina o el área en donde comen que no es precisamente el comedor, si no se trata de ocasiones especiales o cuando hay visitas, es el espacio de reunión familiar por excelencia, aún cuando no se trate de la hora de comer, es el lugar más habitual para platicar o donde se reúnen para hablar de las cosas importantes, una noticia, una tristeza, algún cambio, alguna alegría, o simplemente comentar lo sucedido en ese día.

\section{LA ANTICIPACIÓN DE LO EFÍMERO}

Sí, la actividad es tanto mental como manual en la cocina, todos lo recursos de la inteligencia y la memoria se movilizan ahí, hay que organizar, decidir, prever. Hay que memorizar, adaptar, modificar, inventar, combinar, tomar en cuenta los gustos y las aversiones de los niños, satisfacer gustos, dietas especiales, etc.

En la cocina siempre hay que calcular, calcular tiempo y recursos: no rebasar el presupuesto, no subestimar su propia velocidad de ejecución, no causar el retardo del niño que va a la escuela. Hay que saber evaluar con rapidez lo que resultará más ventajoso, como precio, preparación, sabor. Hay que saber improvisar con brío, cuando la leche se derrama sobre el fuego, cuando ya fuera del paquete y desengrasada la carne se revela insuficiente para cuatro invitados, o cuando algún miembro de la familia invita a un amigo a comer y no queda más remedio que echarle más agua al guisado, rápidamente se 
pasa revisión de todos estos detalles; el juego de las exclusiones, de las imposibilidades y de las preferencias, debe acabar en una propuesta de solución para realizarse sin demora, pues hace falta un menú para el mediodía.

De este modo, hacer de comer, descansa sobre una estructuración compleja de circunstancias y datos objetivos, donde se enmarañan necesidades y libertades, una mezcla confusa y siempre cambiante por medio de la cual se inventan tácticas, se perfilan trayectorias, se individualizan las maneras de hacer de comer.

Quién cocina tiene su repertorio, sus grandes aires operísticos para las circunstancias extraordinarias y sus cancioncillas para el público familiar; sin prejuicios, sin límites pero con sus preferencias y su rutina, sus sueños y sus fobias. A medida que se adquiere experiencia, el estilo se afirma, el gusto se particulariza, la imaginación se libera y la receta pierde su importancia, para sólo ser la ocasión de una invención libre por analogía o asociación de ideas, mediante un juego sutil de sustituciones, de abandonos, añadidos o préstamos. ${ }^{26} \mathrm{Al}$ seguir cuidando la misma receta, dos cocineras o cocineros experimentados obtendrán resultados diferentes, pues intervienen en la preparación el toque personal, el conocimiento o la ignorancia de pequeños secretos de ejecución (enharinar el refractario después de haberle untado mantequilla, para que el fondo de la pasta se seque bien al hornearse), Mi tía F dice: "Cada cocinera tiene sus pequeños secretos, esos hay que guardárselos para que tus invitados queden asombrados, a ustedes se los digo porque somos de la familia, entre nosotras sí se vale..." Toda una relación con las cosas que la receta no codifica y casi no precisa, y cuya manera, de un individuo a otro, difiere pues se arraiga a menudo en la tradición oral, familiar o regional. ${ }^{27}$

Hace ya varios años, en Calvillo, teníamos una vecina quien era originaria del lugar, ella preparaba un mole peculiar del lugar y en algunas ocasiones le mandaba a mi mamá un poco, ella le pidió la

Tomado de: De Certau, Girad y Mayol Pierre, op. cit., p. 202.

27 Ibidem. 
receta y a pesar de prepararlo según sus instrucciones, el sabor quedó distinto. Pareciera ser que esta señora quizá no reveló sus secretos de preparación, su táctica, o tal vez algún ingrediente extra, lo cual implica que la manera en como cada mujer prepara los alimentos le da un toque personal, especial, que la identifica, caracteriza y reconoce generalmente por parte de los hijos: "La comida de mi mamá es la más rica, no se que le pone pero es la que más me gusta, como mi mamá, nadie" (J. Ciudad de Aguascalientes).

La capacidad de transformar los alimentos, la materia prima, en algo totalmente distinto, agradable, deleitable, representa de alguna manera lo que se ve, lo tangible, lo constatable, sin tomar en cuenta todo aquello que tuvo que hacerse para que día con día esa comida llegue a su destino final, los conocimientos, la memoria, los recursos, el tiempo, la creatividad, la dedicación son aspectos que quedan en la invisibilidad, en lo no nombrado, quizá porque sólo dura cuando mucho un par de horas, o porque para el resto de la familia no es importante saber lo que tuvo que pensarse y hacerse para que todos los días sin falta, haya comida en la mesa.

Sólo viviendo este proceso es posible entender lo que implica hacerse cargo de la cocina y hacer de comer, el esfuerzo, la dedicación, el trabajo tanto físico como mental que requiere, la administración, organización, previsión e invención que día a día se llevan a cabo y que sólo estando ahí, siendo parte del proceso mismo, puede valorarse toda esa labor y responsabilidad no reconocida, no apreciada, y que a fin de cuentas perecedera, en palabras de una entrevistada:

Es tan desgastante pasármela dos horas haciendo de comer con todo el amor y la dedicación del mundo, para que en un momento todo se termine, que ni las gracias me den, ni me digan si estaba bueno y sea yo la última en sentarme a comer... (Señora B. Guadalajara).

\section{HACER DE COMER, TRADICIÓN ENTRE MUJERES}

Como se ha venido sosteniendo en varios apartados, la mayoría de las mujeres son quienes se hacen cargo de la cocina y de hacer de comer; éstas al mismo tiempo, involucran a sus hijas, pidiéndoles que les ayuden a realizar diversas tareas. Desde pequeñas se les involucra 
con quehaceres fáciles y pequeños, conforme van creciendo éstos aumentan, ya sea comprando lo que haga falta, lavando los trastes, o elaborando algún platillo por iniciativa propia o por mandato de la madre quien ha decidido que "ya es tiempo que aprenda a cocinar".

Tradicionalmente, en el contexto de Aguascalientes, se asumía que una mujer para poder casarse debía saber cocinar, lavar, planchar, remendar, en fin, todas las llamadas labores del hogar. Hoy en día, esto ya no es considerado como algo tan primordial, ni tan importante para conformar una pareja. Sin embargo, es común observar que las hijas ya casadas consulten a sus madres, tías o abuelas, para preparar determinado platillo; que las mujeres se reúnan en torno a la mesa para hablar de las distintas formas de preparar distintas comidas, pueden pasar horas, dándose consejos, platicando anécdotas, al respecto, pasándose recetas, etcétera.

Esto nos muestra cómo los conocimientos culinarios se van transmitiendo de generación en generación entre las mujeres. Generalmente quien nos enseña a cocinar es nuestra madre al igual que a ella la enseñó su mamá, y a su mamá su abuela, lo cual habla de una sucesión de componentes, colmados de costumbres, tradiciones, prácticas, hábitos, que nos hablan de una biografía personal que pasa a conformar parte de la historia familiar, la cual se va cargando de elementos nuevos, en donde cada mujer, al seguir la receta y consejos de su madre, tía o abuela, agrega su toque personal, un nuevo ingrediente, una nueva forma de hacerlo que resulta más fácil o más práctica y que, en última instancia, viene a conformar la historia de un pueblo, de una ciudad, o de una nación; historia nunca estancada, sino constantemente estructurándose y reestructurándose, de acuerdo a las posibilidades creadoras, imaginativas, económicas, tecnológicas, etcétera, con que las mujeres cuentan para llevar a cabo el minucioso "arte de hacer de comer" en la vida cotidiana.

\section{COMENTARIOS FinALES}

Evidentemente, este trabajo no es concluyente, es una primera aproximación analítica a la temática a partir de un contexto social específico. Pero, aún en éste, existe una gran diversidad en cuanto a las formas de organización del trabajo de las mujeres, tanto dentro como fuera de la

(n)

$$
\text { C }
$$


casa, en los modos de producir y reproducir la vida cotidiana. Si bien algunas se han distanciado de su tradicional centralidad en la cocina, la mujer sigue apareciendo como la figura principal en este espacio cotidiano de la vida privada. Asimismo, a pesar de la preminencia de la cocina y la importancia de las mujeres en este ámbito, se conciben casi al nivel de la invisibilidad. En pocas palabras, al mismo tiempo que las prácticas culinarias se sitúan en el nivel más elemental de la vida cotidiana pero también en el más necesario, son las menos valoradas y reconocidas cultural y socialmente. Es por esto que este trabajo se ha centrado primero en conocer, para después reconocer el valor de cocinar, y valorar el papel medular que las mujeres han tenido en él.

Creo que si bien este trabajo es una contribución mínima al tema, pudiera, al menos, hacer notar la importancia del asunto y servir de base para realizar otros estudios.

(2) 